\title{
Chronic ingestion of deoxynivalenol and fumonisin, alone or in interaction, induces morphological and immunological changes in the intestine of piglets
}

\author{
Ana-Paula F. L. Bracarense ${ }^{1}$, Joelma Lucioli ${ }^{1} \dagger$, Bertrand Grenier ${ }^{2,3} \dagger$, Graziela Drociunas Pacheco ${ }^{1,2}$, \\ Wulf-Dieter Moll $^{3}$, Gerd Schatzmayr ${ }^{3}$ and Isabelle P. Oswald ${ }^{2 *}$ \\ ${ }^{1}$ Universidade Estadual de Londrina, Lab Patologia Animal, Londrina, Brazil \\ ${ }^{2}$ INRA, UMR 1331 ToxAlim, Research Center in Food Toxicology, 180 Chemin de Tournefeuille BP 93173, 31027 Toulouse \\ Cedex 3, Toulouse, France \\ ${ }^{3}$ BIOMIN Research Center, Technopark 1, Tulln, Austria
}

(Submitted 19 April 2011 - Final revision received 2 August 2011 - Accepted 3 August 2011 - First published online 22 September 2011)

\begin{abstract}
Deoxynivalenol (DON) and fumonisins (FB) are mycotoxins produced by Fusarium species, which naturally co-occur in animal diets. The gastrointestinal tract represents the first barrier met by exogenous food/feed compounds. The purpose of the present study was to investigate the effects of $\mathrm{DON}$ and $\mathrm{FB}$, alone and in combination, on some intestinal parameters, including morphology, histology, expression of cytokines and junction proteins. A total of twenty-four 5-week-old piglets were randomly assigned to four different groups, receiving separate diets for 5 weeks: a control diet; a diet contaminated with either DON (3 mg/kg) or FB (6 mg/kg); or both toxins. Chronic ingestion of these contaminated diets induced morphological and histological changes, as shown by the atrophy and fusion of villi, the decreased villi height and cell proliferation in the jejunum, and by the reduced number of goblet cells and lymphocytes. At the end of the experiment, the expression levels of several cytokines were measured by RT-PCR and some of them (TNF- $\alpha$, IL-1 $\beta$, IFN- $\gamma$, IL- 6 and IL-10) were significantly up-regulated in the ileum or the jejunum. In addition, the ingestion of contaminated diets reduced the expression of the adherent junction protein E-cadherin and the tight junction protein occludin in the intestine. When animals were fed with a co-contaminated diet (DON + FB), several types of interactions were observed depending on the parameters and segments assessed: synergistic (immune cells); additive (cytokines and junction protein expression); less than additive (histological lesions and cytokine expression); antagonistic (immune cells and cytokine expression). Taken together, the present data provide strong evidence that chronic ingestion of low doses of mycotoxins alters the intestine, and thus may predispose animals to infections by enteric pathogens.
\end{abstract}

Key words: Multi-contamination: Mycotoxins: Deoxynivalenol: Fumonisins: Intestine: Cellular junctions: Immunity

Mycotoxins are secondary metabolites of various fungi commonly found in feed and foodstuffs. Based on their known and suspected effects on human and animal health, aflatoxin, fumonisin, deoxynivalenol, ochratoxin A and zearalenone are recognised as the five most important agricultural mycotoxins $^{(1)}$. The toxic effects of Fusarium mycotoxins in animals include reduced growth, feed refusal, immunosuppression, gastrointestinal lesions, and neurological and reproductive disorders ${ }^{(2)}$.

Recent surveys ${ }^{(3,4)}$ have demonstrated the regular occurrence of low levels of multiple mycotoxins in cereals. The toxicity of combinations of mycotoxins cannot always be predicted based upon their individual toxicities ${ }^{(5,6)}$.
Interactions between concomitantly occurring mycotoxins can be antagonistic, additive or synergistic. Data on the combined toxic effects of mycotoxins are limited and, therefore, the actual combined health risk from exposure to mycotoxins is unknown ${ }^{(6)}$. Worldwide surveys on the occurrence and contamination levels of mycotoxins in raw materials also indicate that deoxynivalenol (DON) and fumonisins (FB) are the most frequently detected mycotoxins ${ }^{(3,4)}$. It was thus of interest to determine their toxic effect when present simultaneously.

The intestinal tract is the first barrier against ingested antigens, including mycotoxins and pathogenic bacteria. Following ingestion of mycotoxin-contaminated food,

Abbreviations: DON, deoxynivalenol; FB, fumonisins; MIP-1 $\beta$, macrophage inflammatory protein-1 $\beta$

* Corresponding author: Dr I. P. Oswald, email isabelle.oswald@toulouse.inra.fr

† Both authors contributed equally to this study. 
enterocytes may be exposed to high concentrations of toxins $^{(7)}$. A role of food-associated mycotoxins in the induction or persistence of human chronic intestinal inflammatory diseases has also been suspected ${ }^{(8)}$. Studies focusing on the influence of food-derived antigens on intestinal morphology as an indicator of animal health are common; however, there are few publications on the effects of chronic exposure to a mycotoxin co-contaminated diet.

FB are toxic and carcinogenic mycotoxins produced by Fusarium verticillioides and $F$. proliferatum, common pathogens of maize. Acute intoxication with high doses of $\mathrm{FB}(>50 \mathrm{mg} / \mathrm{kg}$ feed) causes porcine pulmonary oedema and equine leukoencephalomalacia ${ }^{(9)}$. Ingestion of lower doses $(5 \mathrm{mg} / \mathrm{kg}$ feed) predisposes pigs to lung pneumonitis $^{(10)}$. In developing countries, an association between human oesophageal cancer and exposure to corn contaminated with about $100 \mathrm{mg}$ fumonisin/kg has been reported ${ }^{(11)}$. By contrast, the effect of chronic exposition to FB on the intestine has been poorly investigated. In vitro, 1-10 $\mu \mathrm{m}$-toxin induce apoptosis, inhibition of proliferation and affect the ability to produce cytokines in cell lines ${ }^{(12-14)}$. In vivo, ingestion of FB induces villous fusion and atrophy, affecting the intestinal absorption of nutrients. Also, it has been shown that $8-10 \mathrm{mg}$ fumonisin/kg feed alters the cytokine profile and decreases the specific antibody response ${ }^{(15,16)}$.

DON causes toxic and immunotoxic effects in a variety of cell systems and animal species ${ }^{(17)}$. DON is produced by $F$. graminearum and $F$. culmorum mainly in wheat, barley and maize. Swine are more sensitive to DON than other species, in part because of differences in the metabolism of DON. Chronic low dietary concentrations $(0.05-2.5 \mathrm{mg} / \mathrm{kg}$ feed) induce anorexia, decreased weight gain and immune alterations, while acute higher doses induce vomiting, haemorrhagic diarrhoea and circulatory shock $^{(17-19)}$. At the cellular level, the main effect is the inhibition of protein synthesis via DON binding to the ribosomes. Low exposure to DON was shown to up-regulate the expression of cytokines and inflammatory genes with concurrent immune stimulation, whereas high exposure promoted leucocyte apoptosis associated with immune suppression $^{(17,20)}$. At the intestinal level, 10-100 $\mu \mathrm{m}-\mathrm{DON}$ were shown to increase the permeability of the epithelium and to induce changes in the expression of claudins, a major component of the tight junctions in in vitro and in vivo models $^{(21-23)}$.

The purpose of the present study was to compare the effects of the low doses of DON and FB when fed to pigs individually and in combination, with particular emphasis on their effects on the intestine. The experimental design was a factorial assay including control feed and feed contaminated with 3 and $6 \mathrm{mg} / \mathrm{kg}$ of DON and $\mathrm{FB}$ individually and in combination, respectively. These contamination levels correspond to levels (1) that frequently occur naturally in cereals and (2) that only induce minimal alteration of zootechnical parameters. We investigated the effect of DON and FB on intestine morphology, on the expression of junction proteins, as well as on the intestinal expression of cytokines.

\section{Materials and methods}

\section{Animals and diets}

A total of twenty-four crossbred castrated male piglets $(10 \cdot 2$ (SEM 1.89) kg body weight) were used in the present study. Pigs were acclimatised for 1 week in the animal facility of the INRA ToxAlim Laboratory (Toulouse, France) before being used in experimental protocols. Animals were kept in batch pens for $35 \mathrm{~d}$. Feed and water were provided ad libitum throughout the experimental period. The animals were subjected to one of four dietary treatments for $35 \mathrm{~d}$ : control diet $(0.5 \mathrm{mg}$ DON $/ \mathrm{kg}$ feed, FB below the limit of detection); diet containing $2.8 \mathrm{mg}$ DON/kg feed; diet containing $5.9 \mathrm{mg}$ $\mathrm{FB} / \mathrm{kg}$ feed $(4.1 \mathrm{mg} \mathrm{FB} 1+1.8 \mathrm{mg}$ FB2); diet containing $3.1 \mathrm{mg} \mathrm{DON}+6.5 \mathrm{mg} \mathrm{FB} / \mathrm{kg}$ feed $(4.5 \mathrm{mg} \mathrm{FB} 1+2.0 \mathrm{mg}$ FB2). The diets were artificially contaminated with the fungal culture material containing DON and FB, as already described $^{(24)}$. The diet formulations and nutrient contents are described in Table 1. Even if the feed intake of the animals was not measured in the experiment, we can estimate that piglets were exposed to 130 and $260 \mu \mathrm{g} / \mathrm{kg}$ body weight per $\mathrm{d}$ of DON and FB, respectively.

Deoxynivalenol, zearalenone and enniatin were found to be naturally present in the cereals used, resulting in the concentrations of 500,50 and $100 \mu \mathrm{g} / \mathrm{kg}$ feed, respectively. All other mycotoxins, including fumonisin, aflatoxins, T-2 toxin, HT-2 toxin and ochratoxin A, were below the limit of detection.

The experimental design used in the present study was entirely randomised with six replicates (each animal representing one replicate). At the end of the experiment, pigs were fasted overnight before being subjected to electrical stunning and euthanised by exsanguination. Samples from

Table 1. Composition of the experimental diet

\begin{tabular}{|c|c|}
\hline \multicolumn{2}{|l|}{ Ingredients (\%) } \\
\hline Wheat & $47 \cdot 50$ \\
\hline Soyabean meal & $24 \cdot 30$ \\
\hline Barley & $22 \cdot 90$ \\
\hline Calcium phosphate & $1 \cdot 12$ \\
\hline Calcium carbonate & 1.00 \\
\hline Vitamin and mineral premix ${ }^{*}$ & 0.50 \\
\hline Vegetable oil & 1.40 \\
\hline $\mathrm{NaCl}$ & 0.40 \\
\hline Phytase & 0.01 \\
\hline Lys & 0.465 \\
\hline Met & 0.165 \\
\hline Thr & 0.195 \\
\hline Tryptophan & 0.045 \\
\hline \multicolumn{2}{|l|}{ Composition† } \\
\hline Starch $(\mathrm{g})$ & $476 \cdot 8$ \\
\hline Crude protein (g) & $218 \cdot 3$ \\
\hline Crude fibre $(\mathrm{g})$ & 37.5 \\
\hline $\mathrm{Ca}(\mathrm{g})$ & $10 \cdot 5$ \\
\hline$P(g)$ & 6.5 \\
\hline $\mathrm{K}(\mathrm{g})$ & $8 \cdot 7$ \\
\hline Net energy (MJ) & $15 \cdot 6$ \\
\hline
\end{tabular}


the mid-jejunum and proximal ileum were collected from each animal from all groups and fixed in $10 \%$ buffered formalin solution for histological analysis. In addition, samples from the same regions of the intestine were collected, flashfrozen in liquid $\mathrm{N}_{2}$ and stored at $-80^{\circ} \mathrm{C}$ until processed for measurements of junction proteins and cytokine mRNA. The institutional Ethics Committee for Animal Experimentation approved the study.

\section{Histological assessment of the intestine}

The tissue pieces fixed in $10 \%$ buffered formalin were dehydrated through graded alcohols and embedded in paraffin wax. Sections $(3 \mu \mathrm{m})$ were stained with haematoxylin-eosin for histopathological evaluation. A lesional score was designed to compare histological changes. The frequency and severity of each lesion were considered in the score, as already described ${ }^{(25)}$. The following criteria were included in the score: morphology of villi; morphology of enterocytes; interstitial oedema; lymph vessel dilation (Table 2). The lesion score was calculated by taking into account the degree of severity (severity factor) and the extent of each lesion (according to intensity or observed frequency, scored from 0 to 3). For each lesion, the score of the extent was multiplied by the severity factor.

To evaluate goblet cell density, sections of the intestine were stained with alcian blue. Positively stained goblet cells were counted randomly in five fields per sample at 40x magnification, and the means were subjected to statistical analysis.

Villi height and crypt depth were measured randomly on thirty villi using a MOTIC Image Plus $2.0 \mathrm{ML}^{\circledR}$ image analysis system (MOTIC Image Plus Motic Instruments, Richmond, Canada). The number of lymphocytes, plasma cells and eosinophils was counted randomly based on morphology on three fields per sample at $40 \times$ magnification. The number of mitotic figures in the enterocytes was counted in twenty fields per slide using $40 \times$ magnification. Each field corresponds to a surface area of $1.5 \mathrm{~mm}^{2}$. The means of lesional score, intestinal morphometry, number of goblet

Table 2. Histological criteria used to establish the intestinal lesional score*

\begin{tabular}{lcc}
\hline Type of lesion & Severity factor & Maximal score \\
\hline Lymphatic vessel dilation & 1 & 38 \\
Cell vacuolation & 1 & \\
Cubic enterocytes & 2 & \\
Villus flattening & 2 & \\
Villus fusion & 2 & \\
Interstitial oedema & 2 & \\
Villi apical necrosis & 3 & \\
\hline
\end{tabular}

* The score for each lesion was obtained by multiplying the severity factor (or degree of severity) with the extent of the lesion. The organ score was then obtained by the sum of each lesion score. Severity factor (or degree of severity) was determined as: 1, mild lesions; 2, moderate lesions. The extent of each lesion (intensity or observed frequency) was evaluated in three slides per animal and scored as: 0 , no lesion; 1 , low extent $(25 \%$ of the intestinal section affected); 2 , intermediate exten (50\% of the intestinal section affected); 3 , large extent $(75 \%$ of the intestinal section affected). Each intestinal section was $1 \mathrm{~cm}^{2}$. cells, inflammatory infiltrate and mitosis were utilised for statistical analysis.

\section{Immunohistochemical assessment of the expression of junction molecules}

E-cadherin expression was analysed on formalin-fixed, paraffinembedded intestinal sections to evaluate intestinal-cell adherens junctions. Tissue sections were deparaffinised with xylene and dehydrated through a graded ethanol series. Heat-mediated antigen retrieval was done by heating the sections (immersed in EDTA buffer, $\mathrm{pH}$ 9.0) in a microwave oven $(750 \mathrm{~W})$ for $15 \mathrm{~min}$. Endogenous peroxidase activity was blocked by incubation in methanol- $\mathrm{H}_{2} \mathrm{O}_{2}$ solution. The sections were incubated overnight at $4{ }^{\circ} \mathrm{C}$ with the primary antibody (diluted 1:50, anti-E-cadherin Clone 4A2C7; Zymed, San Francisco, CA, USA) suitable for the detection of E-cadherin by immunochemistry. The secondary antibody (Kit Super Picture ${ }^{\mathrm{TM}}$; Zymed, South San Francisco, CA, USA) was applied followed by the addition of a chromogen (3,3'-diaminobenzidine). Finally, the tissue sections were counterstained with haematoxylin and mounted on coverslips using a permanent mounting medium. Tissue sections were examined, and the proportion of the intestinal section expressing E-cadherin was estimated. Each sample was assessed as showing either normal or reduced staining. Normal staining was considered when homogeneous and strong basolateral membrane staining of the enterocytes was detected. Heterogeneous and weak staining was considered to indicate reduced expression. The results are reported as the percentage of animals showing strong/homogeneous immunoreactivity to E-cadherin.

\section{Western blot analysis of junction proteins}

Proteins were extracted from the ileum and assayed as described previously ${ }^{(26)}$. Briefly, the extraction was carried out on ice in extraction buffer. The protease inhibitor cocktail (antipain, pepstatin, benzamidine, aminoethyl benzenesulfonyl fluoride hydrochloride, aprotinin and leupeptin) was added to the extraction buffer just before use. Extracts of tissue proteins were then separated by SDS-PAGE. Equal amounts of proteins were loaded on a $12.5 \%$ acrylamide gel. Migration was conducted in $250 \mathrm{~mm}$-Tris buffer ( $\mathrm{pH} 7 \cdot 6$ ) containing $1 \%$ SDS and $1.92 \mathrm{M}$-glycine. After separation, proteins were transferred onto an Optitran BA-S 83 membrane (Whatman $^{\circledR}$, Dassel, Germany). In previous studies ${ }^{(22,26)}$, we have observed that DON decreases the expression of claudins. In the present study, we extended our knowledge concerning the effect of mycotoxins on junction proteins and evaluated the effect of DON and FB on another tight junction protein (occludin) and on an adherens junction protein (E-cadherin). The antibodies used in the present study were E-cadherin (24E10) rabbit mAb (diluted 1:500; Cell Signaling Technology, Danvers, MA, USA), rabbit anti-occludin (672381A, diluted 1:500; Invitrogen, Cergy-Pontoise, France) and $\beta$-actin mouse mAb (8H10D10; Cell Signaling). These antibodies are suitable for the detection of proteins by Western blot. Expression of $\beta$-actin was used for checking the equal protein 
load across gel tracks. Band densities were obtained by scanning the membranes using the Odyssey ${ }^{\circledR}$ Infrared Imaging System (LI-COR; ScienceTec, Les Ulis, France). Density data were standardised within membranes by expressing the density of each band of interest relative to that of $\beta$-actin in the same lane.

\section{Determination of the expression of MRNA encoding for cytokines by real-time PCR}

Tissue RNA was processed in lysing matrix D tubes (MP Biomedicals, Illkirch, France) containing guanidine thiocyanate-acid phenol (Extract-All ${ }^{\circledR} ;$ Eurobio, les Ulis, France) for use with the FastPrep-24 (MP Biomedicals, Illkirch, France). Concentration, integrity and quality of RNA were determined spectrophotometrically (optical density at $260 \mathrm{~nm}$ ) using Nanodrop ND1000 (Labtech International, Paris, France). In addition to this assessment, $200 \mathrm{ng}$ RNA were analysed by electrophoresis. The reverse transcription of $2 \mu \mathrm{g}$ of total RNA was performed using M-MLV RT (Rnasin ${ }^{\circledR}$ plus; Promega, Charbonnière, France) and random primers $\left(5 \mathrm{~min}\right.$ at $37^{\circ} \mathrm{C}, 1 \mathrm{~h}$ at $42^{\circ} \mathrm{C}, 15 \mathrm{~min}$ at $70^{\circ} \mathrm{C}$; Invitrogen), as already described ${ }^{(27)}$. Real-time PCR assays were performed on $8 \mathrm{ng}$ cDNA (RNA equivalent) in a $25 \mu \mathrm{l}$ volume reaction per well using the Power SYBR ${ }^{\circledR}$ Green PCR Master Mix as the reporter dye and the automated photometric detector ABI Prism 7000 Sequence Detection System for data acquisition (Applied Biosystems, Courtaboeuf, France). The amplification conditions were as follows: $95^{\circ} \mathrm{C}$ for $10 \mathrm{~min}$ followed by forty cycles of $95^{\circ} \mathrm{C}$ for $15 \mathrm{~s}$ and $60^{\circ} \mathrm{C}$ for $1 \mathrm{~min}$. RNA non-reverse transcript was used as a non-template control to verify that no genomic DNA amplification signal existed. Specificity of PCR products was checked at the end of the reaction by analysing the curve of dissociation. In addition, the size of amplicons was verified by electrophoresis. The sequences and concentration of the primers used are detailed in Table 3. Primers for macrophage inflammatory protein- $1 \beta$ (MIP-1 $\beta$ ), IL-8 and IL-6 detection were designed using Primer Express ${ }^{\circledR}$ software (Applied Biosystems). Primers were purchased from Invitrogen. Amplification efficiency and initial fluorescence were determined by the DART-PCR method, and the values obtained were then normalised by two housekeeping genes, $\beta 2$-microglobulin and ribosomal protein L32; and finally, gene expression was calculated relative to the control group, as already described ${ }^{(28)}$.

\section{Statistical analysis}

Data are presented as means with their standard errors. They were analysed with Statview software, version 5.0 (SAS Institute, Inc., Cary, NC, USA), using ANOVA, Tukey's and PLSD Fisher's tests. Data from immunohistochemical analysis were evaluated using Fisher's test. $P$ values $<0.05$ were considered significant.

\section{Results}

\section{Individual or combined effects of deoxynivalenol and fumonisins on the histology and morphometry of the intestine}

Ingestion of the diet contaminated with $\mathrm{DON}$ and $\mathrm{FB}$, alone or in interaction, did not significantly modulate animal weight. The initial and final body weights of animals in the different groups were 9.54 (SEM 0.99) and 30.50 (SEM 1.34) kg for the control group, 10.46 (SEM 1.24) and 28.98 (SEM 1.75) kg for the DON-treated group, 9.52 (SEM 0.37 ) and 31.12 (SEM $1.63) \mathrm{kg}$ for the FB-treated group and $10 \cdot 16$ (SEM 0.42) and

Table 3. Nucleotide sequences of primers for real-time PCR

\begin{tabular}{|c|c|c|c|}
\hline Gene & Primer sequence & GenBank no. & References \\
\hline RPL32 & $\begin{array}{c}\text { F (300 nм) TGCTCTCAGACCCCTTGTGAAG } \\
\text { R (300 nм) TTTCCGCCAGTTCCGCTTA }\end{array}$ & NM_001001636 & Pinton et al. ${ }^{(26)}$ \\
\hline ß2-Microglobulin & $\begin{array}{c}\text { F (900 nм) TTCTACCTTCTGGTCCACACTGA } \\
\text { R (300 nм) TCATCCAACCCAGATGCA }\end{array}$ & NM_213978 & Devriendt et al. ${ }^{(28)}$ \\
\hline IL-12p40 & $\begin{array}{l}\text { F (300 nM) GGTTTCAGACCCGACGAACTCT } \\
\text { R (900 nM) CATATGGCCACAATGGGAGATG }\end{array}$ & NM_214013 & Devriendt et al. ${ }^{(28)}$ \\
\hline IL-8 & $\begin{array}{l}\text { F (300 nм) GCTCTCTGTGAGGCTGCAGTTC } \\
\text { R (900 nм) AAGGTGTGGAATGCGTATTTATGC }\end{array}$ & NM_213867 & Grenier et al. $^{(24)}$ \\
\hline$I L-1 \beta$ & $\begin{array}{l}\text { F (300 nM) GAGCTGAAGGCTCTCCACCTC } \\
\text { R (300 nM) ATCGCTGTCATCTCCTTGCAC }\end{array}$ & NM_001005149 & Devriendt et al. ${ }^{(28)}$ \\
\hline MIP-1 $\beta$ & $\begin{array}{l}\text { F (300 nm) AGCGCTCTCAGCACCAATG } \\
\text { R (300 nm) AGCTTCCGCACGGTGTATG }\end{array}$ & AJ311717 & Grenier et al. ${ }^{(24)}$ \\
\hline IL-6 & $\begin{array}{l}\text { F (300 nM) GGCAAAAGGGAAAGAATCCAG } \\
\text { R (300 nM) CGTTCTGTGACTGCAGCTTATCC }\end{array}$ & NM_214399 & Grenier et al. ${ }^{(24)}$ \\
\hline$I F N-\gamma$ & $\begin{array}{c}\text { F (300 nM) TGGTAGCTCTGGGAAACTGAATG } \\
\text { R (300 nM) GGCTTTGCGCTGGATCTG }\end{array}$ & NM_213948 & Royaee et al. ${ }^{(54)}$ \\
\hline$T N F-\alpha$ & $\begin{array}{l}\text { F (300 nм) ACTGCACTTCGAGGTTATCGG } \\
\text { R (300 nм) GGCGACGGGCTTATCTGA }\end{array}$ & NM_214022 & Meissonnier et al. ${ }^{(55)}$ \\
\hline$I L-2$ & $\begin{array}{l}\text { F (300 nM) GCCATTGCTGCTGGATTTAC } \\
\text { R (300 nM) CCCTCCAGAGCTTTGAGTTC }\end{array}$ & AY294018 & Meurens et al. ${ }^{(56)}$ \\
\hline IL-10 & $\begin{array}{l}\text { F (300 nM) GGCCCAGTGAAGAGTTTCTTTC } \\
\text { R (300 nM) CAACAAGTCGCCCATCTGGT }\end{array}$ & NM_214041 & Present study \\
\hline
\end{tabular}

RPL32, ribosomal protein L32; F, forward; R, reverse; MIP-1 $\beta$, macrophage inflammatory protein-1 $\beta$. 

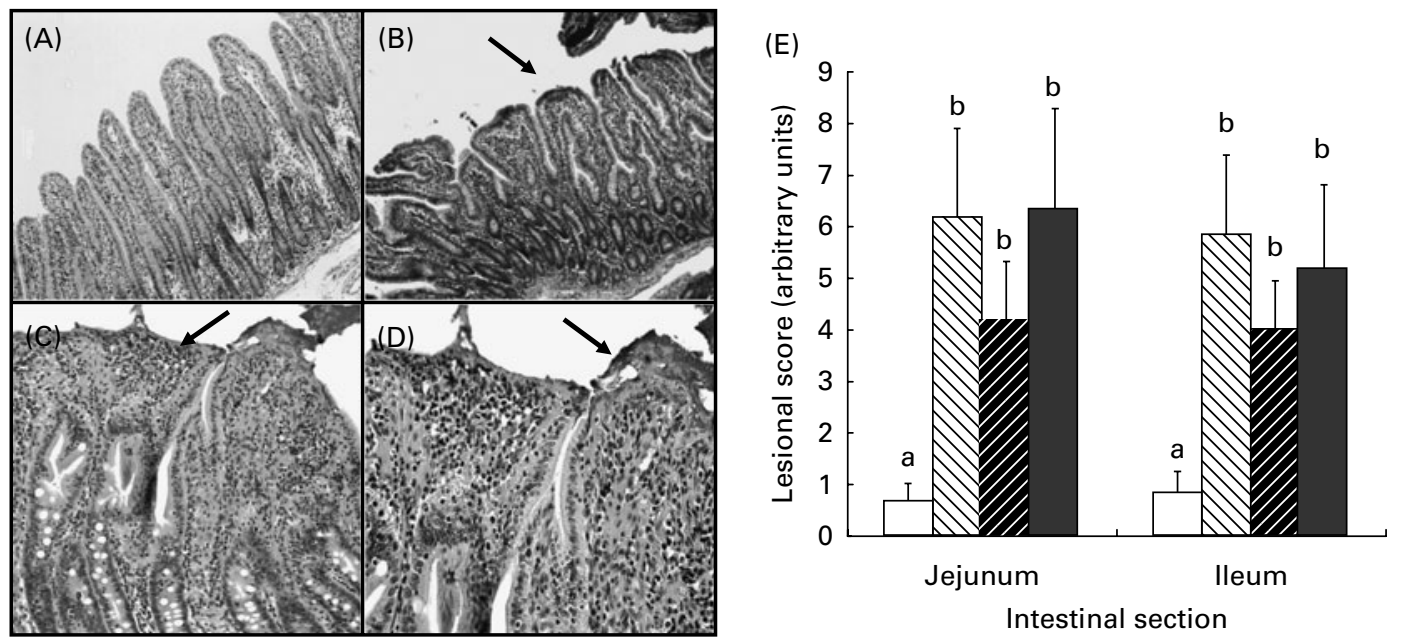

Fig. 1. Effect of individual and combined deoxynivalenol (DON) and fumonisins (FB) exposure on jejunum and ileum histology. Pigs received a control diet ( $\square$ ) or a diet contaminated with DON $(\mathbb{\nabla})$, FB $(\mathbb{Z})$, or both DON and FB $(\square)$. Jejunum of $(A)$ a control piglet and $(B)$ a DON-treated piglet. Villi flattening (arrow). Haematoxylin-eosin (HE), 10x. (C) Villi apical necrosis (arrow). HE, 10x. (D) Bacterial adhesion in the area with necrosis (arrow). HE, 40X. (E) Lesional score after histological examination according to the occurrence and the severity of lesions. Values are means with standard errors of the mean represented by vertical bars ( $n 6$ animals). ${ }^{\mathrm{a}, \mathrm{b}}$ Mean values with unlike letters were significantly different $(P<0.05)$.

28.92 (SEM 1.91) kg for the DON + FB-treated group (NS). In addition, no overall sign of toxicity was observed in animals from the different groups.

Samples of the jejunum and ileum were collected for histomorphometrical analysis. Piglets fed the diets contaminated with mycotoxins showed mild to moderate intestinal lesions. The main histological changes observed were multifocal atrophy and villi fusion, apical necrosis of villi, cytoplasmatic vacuolation of enterocytes and oedema of lamina propria. Lymphatic vessel dilation and prominent lymphoid follicles were also observed. As indicated by the lesional scores, piglets fed mycotoxin-contaminated diets (DON, FB or $\mathrm{DON}+\mathrm{FB}$ ) displayed significant jejunal and ileal lesions when compared with animals fed the control diet (Fig. 1).

Changes in villous height reflect changes in the balance between epithelial cell proliferation and apoptosis. As shown in Fig. 2, villi height decreased significantly in the jejunum of the animals that received DON- or DON + FB-contaminated diet when compared with the control piglets. No change in crypt depth was observed in any intestinal region. Goblet cells synthesise and secrete mucin, which is involved in gut barrier function. The number of goblet cells decreased significantly in the jejunum and the ileum of piglets fed DON- or FB + DON-contaminated diet, respectively (Fig. 3).

Increased numbers of lymphocytes, plasma cells and eosinophils were observed in all regions of the intestine. In the groups receiving a mycotoxin-contaminated diet, a reduction in lymphocytic infiltration was observed in both regions of the intestine. However, this decrease was only significant in the jejunum of DON-treated animals and in the ileum of DON + FB-treated piglets (Fig. 3). By contrast, the number of plasma cells and eosinophils in the lamina propria increased significantly in the jejunum of animals fed the FBcontaminated diet.

\section{Individual or combined effects of deoxynivalenol and fumonisins on intestinal cell proliferation}

Epithelial cell proliferation was estimated by counting the number of mitosis figures in the enterocytes on haematoxylineosin-stained slides. The mean number of mitosis per microscopic field in the jejunum was 2.36 (SEM 1.64) in the control group, 1.73 (SEM 1.35) in the DON-treated group,

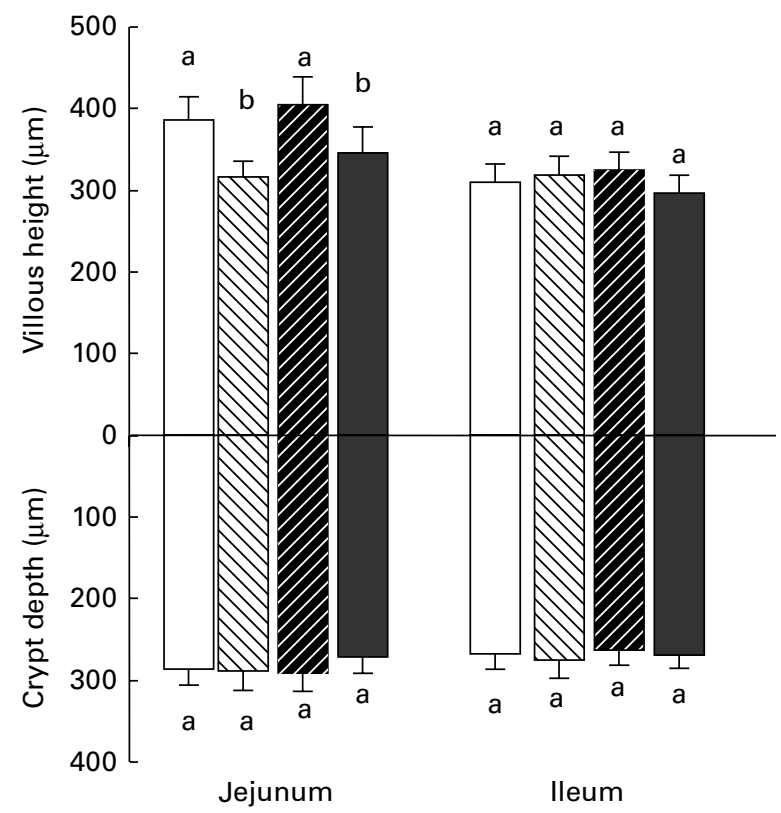

Fig. 2. Effect of individual and combined deoxynivalenol (DON) and fumonisins (FB) exposure on jejunum and ileum villi height and crypt depth. Pigs received a control diet $(\square)$ or a diet contaminated with DON $(\mathbb{\nabla})$, FB $(\mathbb{Z})$, or both DON and FB $(\square)$. Values are means height and depth $(\mu \mathrm{m})$ with their standard errors of the mean represented by vertical bars ( $n 6$ animals). ${ }^{\mathrm{a}, \mathrm{b}}$ Mean values with unlike letters were significantly different $(P<0.05)$. 
(A)

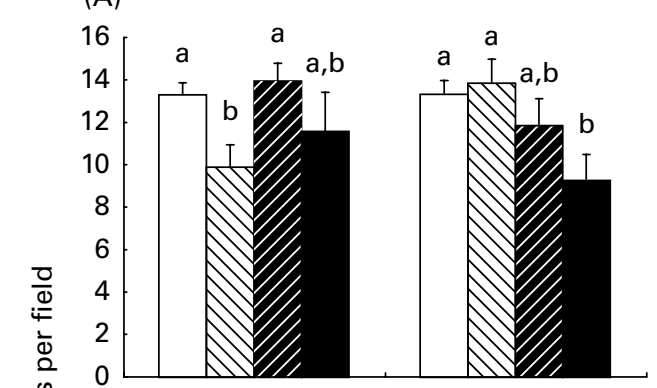

1.66 (SEM 1.11) in the FB-treated group and 1.91 (SEM 1.19) in the DON + FB-treated group. In the ileum, the mean number of mitosis per microscopic field $\left(1.5 \mathrm{~mm}^{2}\right)$ was 1.75 (SEM 1.26), 1.78 (SEM 1.46), 1.62 (SEM 1.17) and 1.89 (SEM 1.11) for the control group, DON-treated group, FB-treated group and DON + FB-treated group, respectively. A significant decrease $(P<0.05)$ was observed in the jejunum of the groups fed mono-contaminated diets compared with the control group.

\section{Individual or combined effects of deoxynivalenol and} fumonisins on intestinal immune response

To evaluate the mechanisms of porcine intestinal defence against mycotoxin exposure, we quantified the expression of genes coding for pro-inflammatory cytokines. Table 4 describes the expression of nine cytokines (IFN- $\gamma$, IL-1 $\beta$, IL-2, IL-6, IL-8, IL-10, IL-12p40, MIP-1 $\beta$ and TNF- $\alpha$ ) in the jejunum and the ileum of piglets exposed to DON and $\mathrm{FB}$ alone or in combination.

Despite an important variability, all the cytokines assessed showed a tendency and/or significant increase of their expression in intestinal samples from piglets receiving mycotoxin-contaminated diets. However, expression of cytokines revealed different profiles according to treatments and intestinal region. DON induced a significant induction of the expression of IL-1 $\beta$, IL-2, IL-6, IL-12p40 and MIP-1 $\beta$ in the jejunum, and a significant induction of the expression of TNF- $\alpha$, IL- $1 \beta$ and IL- 6 in the ileum. By contrast, ingestion of FB-contaminated feed had only a moderate effect on the
(B)

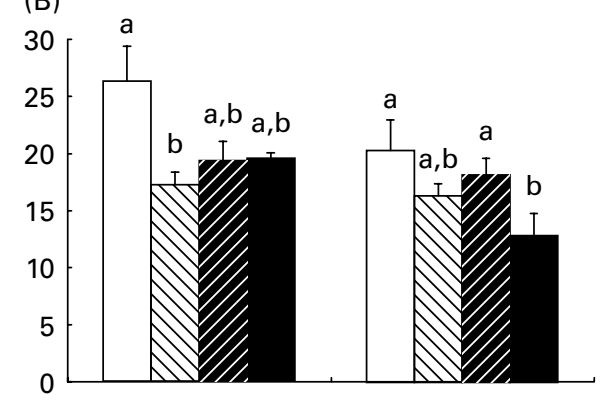

(D)

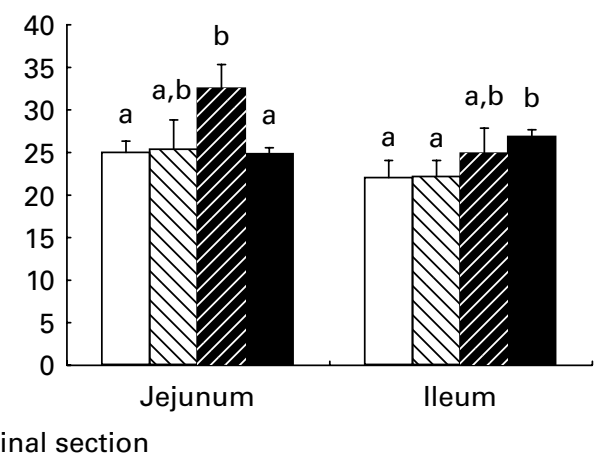

expression of cytokines. It included a significant expression of IL-10 and IFN- $\gamma$ in the jejunum and the expression of TNF- $\alpha$ and IL- $1 \beta$ in the ileum. When animals were given the $\mathrm{DON}+\mathrm{FB}$ co-contaminated diet, the expression of TNF- $\alpha$ and IL-1 $\beta$ in their ileum and the expression of IL-10, IFN- $\gamma$, IL-1 $\beta$, MIP-1 $\beta$, IL-2 and IL-12p40 in their jejunum were not different from the one observed in the intestine of animals fed the mono-contaminated diet. Of note, the expression of IL- 6 was only up-regulated after ingestion of the DONcontaminated diet $(+117 \%$ in the jejunum and $+113 \%$ in the ileum when compared with animals receiving the control feed).

\section{Individual or combined effects of deoxynivalenol and fumonisins on the intestinal expression of junction proteins}

The adherence of the enterocytes and the permeability of the intestinal epithelium are formed to a large extent by multi-protein junction complexes. The expression of two junction proteins, E-cadherin and occludin, was analysed in the ileum of animals by Western blotting. After normalisation by the housekeeping protein $\beta$-actin, the data revealed a significant decrease in the expression of both proteins in animals receiving mycotoxin-contaminated diets compared with those receiving a control diet (Fig. 4).

As Western blot indicated a significant decrease in the total amount of E-cadherin expression in the ileum, we decided to evaluate the expression of this protein in the enterocytes, 
Table 4. Effect of individual and combined deoxynivalenol (DON) and fumonisins (FB) exposure on the jejunum and ileum mRNA expression of cytokines

(Mean values with their standard errors, $n 5$ animals)

\begin{tabular}{|c|c|c|c|c|c|c|c|c|}
\hline \multirow[b]{3}{*}{ Cytokine } & \multicolumn{8}{|c|}{ Diet treatment } \\
\hline & \multicolumn{2}{|c|}{ Control } & \multicolumn{2}{|c|}{ DON } & \multicolumn{2}{|c|}{ FB } & \multicolumn{2}{|c|}{$\mathrm{DON}+\mathrm{FB}$} \\
\hline & Mean & SEM & Mean & SEM & Mean & SEM & Mean & SEM \\
\hline \multirow{2}{*}{\multicolumn{9}{|c|}{$\begin{array}{l}\text { Intestinal portion } \\
\text { Jejunum }\end{array}$}} \\
\hline & & & & & & & & \\
\hline IL-1 $\beta$ & $1.00^{\mathrm{a}}$ & 0.17 & $1.78^{b}$ & 0.12 & $1 \cdot 34^{\mathrm{a}}$ & 0.11 & $1.46^{\mathrm{a}, \mathrm{b}}$ & 0.14 \\
\hline TNF- $\alpha$ & $1.00^{\mathrm{a}}$ & 0.08 & $1 \cdot 29^{\mathrm{a}}$ & 0.12 & $0.88^{a}$ & 0.14 & $1.56^{\mathrm{a}}$ & 0.33 \\
\hline IL-6 & $1.00^{\mathrm{a}}$ & 0.12 & $2 \cdot 17^{\mathrm{b}}$ & 0.30 & $1 \cdot 14^{\mathrm{a}}$ & 0.11 & $1.35^{\mathrm{a}}$ & 0.14 \\
\hline IL-8 & $1.00^{\mathrm{a}}$ & 0.09 & $1.78^{\mathrm{a}}$ & 0.52 & $1.38^{\mathrm{a}}$ & 0.40 & $1.02^{\mathrm{a}}$ & 0.12 \\
\hline MIP-1 $\beta$ & $1.00^{\mathrm{a}}$ & 0.08 & $1.42^{\mathrm{b}}$ & 0.14 & $1.36^{a b}$ & 0.18 & $1.27^{\mathrm{a}, \mathrm{b}}$ & 0.16 \\
\hline IL-2 & $1.00^{a}$ & 0.16 & $1 \cdot 80^{\mathrm{b}}$ & 0.25 & $1.74^{a}$ & 0.31 & $1.56^{a, b}$ & 0.26 \\
\hline IL-12p40 & $1 \cdot 00^{a}$ & 0.09 & $1.71^{\mathrm{b}}$ & 0.26 & $1.36^{\mathrm{a}}, \mathrm{b}$ & 0.13 & $2 \cdot 01^{\mathrm{b}}$ & 0.49 \\
\hline IFN- $\gamma$ & $1.00^{\mathrm{a}}$ & 0.16 & $1 \cdot 29^{a, b}$ & 0.08 & $1.43^{\mathrm{b}}$ & 0.10 & $1 \cdot 35^{a, b}$ & 0.17 \\
\hline IL-10 & $1.00^{\mathrm{a}}$ & 0.11 & $1 \cdot 34^{a, b}$ & 0.24 & $1.51^{\mathrm{b}}$ & 0.19 & $1.63^{b}$ & 0.17 \\
\hline \multicolumn{9}{|l|}{ Ileum } \\
\hline IL-1 $\beta$ & $1.00^{a}$ & 0.19 & $2 \cdot 00^{\mathrm{b}}$ & 0.19 & $1.73^{\mathrm{b}}$ & 0.24 & $1.63^{\mathrm{b}}$ & 0.13 \\
\hline TNF- $\alpha$ & $1.00^{\mathrm{a}}$ & 0.08 & $1.49^{\mathrm{b}}$ & 0.10 & $1.42^{\mathrm{b}}$ & 0.11 & $1 \cdot 71^{\mathrm{b}}$ & 0.23 \\
\hline IL-6 & $1.00^{\mathrm{a}}$ & 0.20 & $2 \cdot 13^{b}$ & 0.21 & $1.02^{\mathrm{a}}$ & 0.13 & $0.96^{a}$ & 0.24 \\
\hline IL-8 & $1 \cdot 00^{\mathrm{a}}$ & 0.18 & $1 \cdot 18^{\mathrm{a}}$ & 0.08 & $1.48^{\mathrm{a}}$ & 0.38 & $1.53^{\mathrm{a}}$ & 0.30 \\
\hline MIP-1 $\beta$ & $1.00^{\mathrm{a}}$ & 0.06 & $1.50^{\mathrm{a}}$ & 0.30 & $1 \cdot 19^{a}$ & 0.07 & $1.42^{\mathrm{a}}$ & 0.22 \\
\hline IL-2 & $1.00^{a}$ & 0.12 & $1.00^{\mathrm{a}}$ & 0.22 & $1.25^{\mathrm{a}}$ & 0.16 & $1.04^{\mathrm{a}}$ & 0.11 \\
\hline IL-12p40 & $1 \cdot 00^{\mathrm{a}}$ & 0.07 & $1.04^{a}$ & 0.11 & $1.09^{a}$ & 0.07 & $1 \cdot 34^{\mathrm{a}}$ & 0.14 \\
\hline IFN- $\gamma$ & $1.00^{\mathrm{a}}$ & 0.12 & $1.43^{\mathrm{a}}$ & 0.21 & $1.26^{a}$ & 0.09 & $1.90^{\mathrm{a}}$ & 0.48 \\
\hline IL-10 & $1.00^{\mathrm{a}}$ & 0.13 & $1 \cdot 14^{\mathrm{a}}$ & 0.12 & $1 \cdot 23^{\mathrm{a}}$ & 0.14 & $1.57^{\mathrm{a}}$ & 0.38 \\
\hline
\end{tabular}

a,b Mean values with unlike superscript letters were significantly different for each cytokine $(P<0.05)$.

using an immunohistochemical assay. The expression of E-cadherin in the jejunum and ileum was significantly reduced in the groups that received the mono-contaminated or cocontaminated diets (Fig. 5).

\section{Discussion}

Co-contamination of grains and feed has been frequently reported worldwide and the occurrence of single-mycotoxin contamination seems to be $\operatorname{rare}^{(3,29)}$. However, most studies investigating the toxic effect of mycotoxins have been performed with feed spiked with a single mycotoxin at high dose. It was thus of interest to determine the effect of the ingestion of feed contaminated with more than one mycotoxin on the intestine. The intestine is the first barrier against mycotoxins and could be exposed to high doses of these toxins ${ }^{(7)}$. In the present study, we have investigated the effect of $\mathrm{FB}$ and DON on the intestine of piglets in order to determine whether they have additive, synergistic or antagonistic effects. FB and DON act through different mechanisms on the intestinal tract. FB blocks sphingolipid synthesis that is essential for the formation of cell membranes, while DON inhibits protein synthesis via ribosome binding ${ }^{(17,30,31)}$.

We did not observe any effect of the mycotoxin-contaminated diets (DON, FB and DON + FB) on the body-weight gain of the animals. Considering the low contamination levels we used, these results are not surprising ${ }^{(15,18,24)}$. The main histological findings observed were villi flattening, apical necrosis and a reduction in the number of goblet cells. Decreased villi height was only significant in the jejunum of piglets fed with the diet mono-contaminated with DON and the diet co-contaminated with DON + FB. Similar changes were observed during in vivo and ex vivo exposure of the intestine to $\mathrm{DON}^{(25,32)}$. The mode of the toxic action of DON is the inhibition of protein synthesis, thus primarily affecting rapidly dividing cells such epithelial and immune cells ${ }^{(17,20)}$. Villi flattening in the jejunum is probably due to the impairment of cell proliferation, as could be observed by the decrease in the number of mitotic figures in the same region.

The number of goblet cells in the intestinal wall reflects the intestinal potential of mucin production. The large protein synthesis load of these secretory cells renders them susceptible to endoplasmic reticulum stress ${ }^{(33)}$. Considering that the decrease in goblet cell density was not related to villi flattening (data not shown), we can hypothesise that DON in mucus-producing cell lines induces endoplasmic reticulum stress, leading to changes in intestinal cell density. Hyperplasia of intestinal goblet cells has been observed in piglets and broiler chicks receiving feed contaminated with 30 and $300 \mathrm{mg} \mathrm{FB} / \mathrm{kg}$ feed, respectively ${ }^{(34,35)}$. In the present study, a decrease in the number of goblet cells was observed in piglets fed the DON-contaminated and the DON + FB CO-contaminated diets, while in animals receiving the FB-contaminated diet, no effect was observed. The difference in the effect of FB on goblet cells could be due to the low dose of FB used in the present experiment. Intestinal mucus protects the epithelium against adhesion and invasion by pathogens ${ }^{(30)}$; therefore, a reduction in the number of goblet cells can affect the intestinal barrier function. The mechanisms involved in the alterations on the production and composition of the intestinal mucus layer by mycotoxins are still unknown and further studies are required. 
(A)

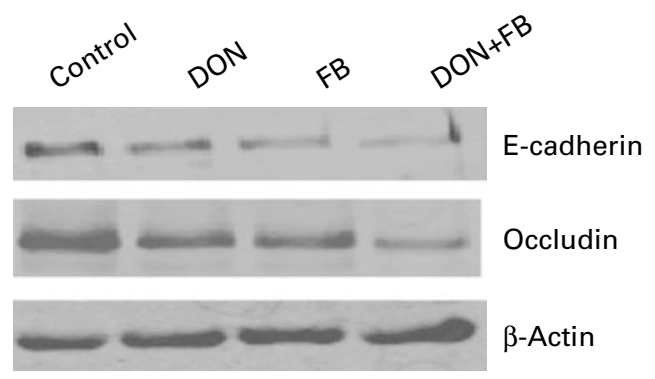

(B)

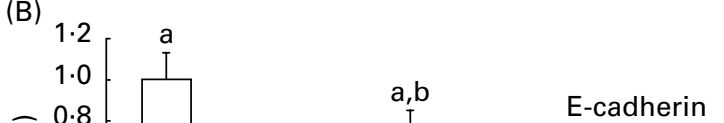

Controversial results have been reported with respect to intestinal proliferation in in vivo and in vitro studies during mycotoxicosis. In the present study, we evaluated cell proliferation by counting mitotic figures in intestinal crypts, and we observed a significant decrease in proliferating cells in the jejunum of the FB- and DON-treated groups. Other studies have demonstrated that subchronic exposure to $\mathrm{FB}$ or DON and other mycotoxins increases the number of mitotic figures $^{(33,36)}$. This difference could be due to the animal model used as well as the dose and duration of the experiment. Despite very different modes of action, both DON and FB have been found to decrease the proliferation of intestinal epithelial cells. Indeed, Bouhet et al. ${ }^{(37)}$ observed a decrease in the proliferation of porcine intestinal epithelial cells treated with $\mathrm{FB}_{1}$ in vitro due to a blockade in the G0/G1 cell-cycle phase. Similarly, van de Walle et al. ${ }^{(23)}$ detected an in vitro decrease in the proliferation, associated with an inhibition of protein synthesis, of human intestinal epithelial cells treated with DON.

Mononuclear and eosinophil inflammatory infiltrate has been reported during $\mathrm{FB}$ mycotoxicosis in several animal species. In addition, proliferation of lymphoid nodules in the ileum and caecum has also been observed ${ }^{(35,37)}$. We have shown that DON and DON + FB induced a significant decrease in the number of lymphocytes in the jejunum and ileum, whereas FB induced a significant increase in eosinophils and plasma cells in the jejunum. Lymphocyte depletion of lymph nodes and spleen has been reported in young pigs fed a diet contaminated with DON and zearalenone ${ }^{(38)}$. Studies of macrophages and lymphocytes have shown that the trichothecene-mediated immunosuppressive effect was associated with the induction of apoptosis by the activation of c-Jun terminal kinase, p38 mitogen-activated protein kinase and caspases ${ }^{(20,39)}$. Because lymphoid cells are constantly renewing, lymphocytes could be particularly sensitive to DON. On the other hand, DON stimulates the production of mucosal antibodies by plasma cells through the upregulation of pro-inflammatory cytokines ${ }^{(17,18)}$.

In the present study, exposure of piglets to the chronic doses of FB, DON or both in the feed induced the activation of the pro-inflammatory cytokine network in the intestine. As already described in rodents ${ }^{(17,20)}$, we have observed that DON specifically induced the expression of IL- 6 . This can be related to the specific effect of DON on IgA synthesis that has been observed on DON-treated animals ${ }^{(18,24)}$. A proinflammatory effect has also been observed in human enterocytes exposed to DON, as demonstrated by an increased expression of IL- $8^{(21,23)}$. It has been established that the intestine has its own immune network, which can cause localised induction of various cytokines and chemokines ${ }^{(40)}$ Increases in intestinal cytokine mRNA profile indicative of macrophage and TH1 activation have been reported after DON and FB exposure ${ }^{(41-43)}$. TNF- $\alpha$ and IL-1 $\beta$ are known to induce apoptosis via the receptor-ligand-mediated mechanism $^{(41,44)}$. We hypothesise that, besides the known apoptotic mechanisms ${ }^{(13,20)}$, FB and DON could induce TNF-mediated lymphocyte and epithelial apoptosis in the intestine, which could explain the decrease in the number of these cells observed in exposed pigs. A relationship between clinically relevant concentrations of TNF- $\alpha$ and IL- $1 \beta$ and an increase in intestinal tight junction permeability has been demonstrated in Caco-2 cells ${ }^{(45,46)}$. With regard to this association, we can consider that the increased levels of TNF- $\alpha$ and IL-1 $\beta$ observed after the ingestion of $\mathrm{DON}$ and $\mathrm{FB}$ in the ileum could also contribute to tight-junction ileal barrier defects.

In previous studies ${ }^{(22,26)}$, we have observed that DON decreases the expression of claudins. In the present study, we observed that other junction proteins, such as occludin and E-cadherin, were also affected by exposure to mycotoxins. To the best of our knowledge, this is the first study reporting a reduced expression of E-cadherin in the intestinal tract after ingestion of a mycotoxin-contaminated diet. The reduction of E-cadherin and occludin suggests a loss of enterocytes' adhesive properties that would correlate with an increased intestinal translocation of toxic luminal antigens, promoting intestinal inflammation ${ }^{(8)}$, with an abnormal delivery of antigens via a paracellular pathway ${ }^{(47,48)}$, and with an increased susceptibility to enteric infections ${ }^{(21,30)}$.

One of the aims of the present study was to assess the combined effect of DON and FB. The interaction between 

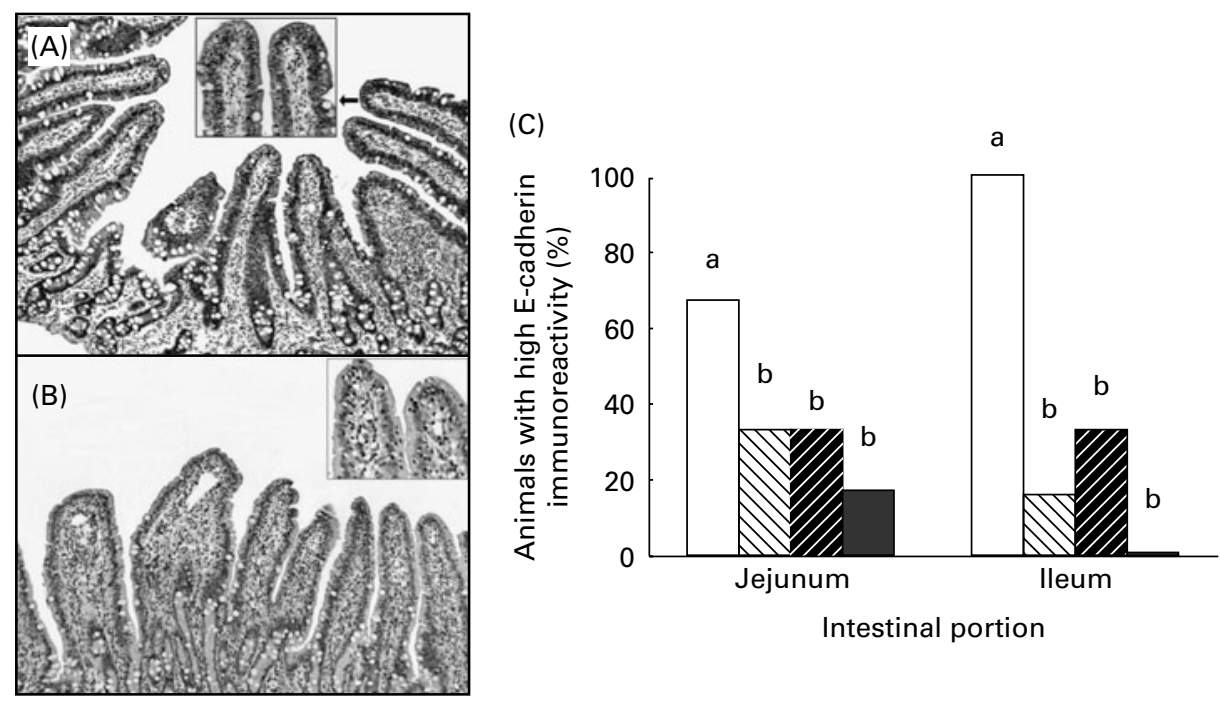

Fig. 5. Effect of individual and combined deoxynivalenol (DON) and fumonisins (FB) exposure on the intestinal expression of E-cadherin. Pigs received a control diet $(\square)$, or a diet contaminated with DON $(\mathbb{\nabla})$, FB $(\mathbb{Z})$, or both DON and FB $(\square)$. (A) Jejunum of a control piglet showing a strong and (B) homogeneous immunoreactivity to E-cadherin. Immunoperoxidase, 20x. (C) Percentage of animals showing strong immunoreactivity to E-cadherin. ${ }^{a, b}$ Mean values with unlike letters were significantly different $(P<0.05)$.

the toxins can be classified in four different categories: synergistic, additive, less-than-additive or antagonistic effects ${ }^{(6)}$. In the present study, we observed synergistic interactions in the number of goblet cells and eosinophils in the ileum, additive interactions in the expression of IL-10, TNF- $\alpha$ and adherent proteins, less-than-additive interactions in the expression of IFN- $\gamma$ and in lesion scores, and antagonistic interactions for some cell populations (goblet cells, plasma cells, eosinophils and lymphocytes in the jejunum) and some cytokine expression (IL-1 $\beta$ and IL-6). It is commonly assumed that mycotoxins with the same mode of action and/or with the same cellular target would have a synergistic or additive effect when present together ${ }^{(50)}$. DON and FB specifically target activated or renewing cells, thus they may affect intestinal cells (lymphocytes, goblet cells or enterocytes). At the molecular level, exposure to either DON or FB quickly results in the activation of mitogen-associated protein kinase ${ }^{(20,26,51)}$ that are known to modulate numerous physiological processes, such as cell growth, apoptosis or immune response ${ }^{(52)}$. This might explain the synergistic and additive interaction that we observed at the intestinal level. The effect in the mitogenassociated protein kinase network cannot explain the other interactions that we observed and we do not have a simple hypothesis to propose. Indeed, many different factors may influence the outcome of an interaction, such as the endpoint assessed, the doses and the species used, or the time and route of exposure.

When the same animals as the ones used in the present study were analysed for their blood neutrophil counts, their lymphocyte proliferation or their kidney lesion, a less-thanadditive interaction was observed ${ }^{(24)}$. An additive effect of the toxins has been determined for the liver and the lung lesions, the synthesis of specific antibody and the expression of cytokines in the spleen ${ }^{(24)}$. In the present study, we observed that $\mathrm{FB}$ was able to prevent the DON-induced intestinal expression of IL-6. The same antagonistic interaction between these mycotoxins has already been detected for the serum level of $\operatorname{IgA}{ }^{(24)}$. Considering that IL-6 is driving the synthesis of $\operatorname{IgA}{ }^{(53)}$, it is more than likely that the ability of FB to prevent the DON-induced expression of IgA is due to its effect on IL-6 synthesis.

Multi-contamination with low doses of mycotoxins is more likely to occur in naturally contaminated cereals, but only a few studies have investigated the effects of co-contaminated mycotoxin diets in pigs ${ }^{(6)}$. Taken together, the present data provide strong evidence that chronic ingestion of low doses of mycotoxins induces tissue lesions, modulates the immune cell count as well as the cytokine synthesis, and decreases the expression of proteins involved in cell adhesion. This suggests that ingestion of feed contaminated with these toxins may predispose animals to infections by enteric pathogens through an alteration of intestinal barrier function.

\section{Acknowledgements}

B. G. was supported by a doctoral fellowship (CIFRE 065/2007), jointly financed by the Biomin company, ANRT (Association Nationale de la Recherche Technique) and INRA (Institut National de la Recherche Agronomique). This study was supported in part by grant no. 593/08 from CAPES/ COFECUB, grant no. 472048/2008-2 from CNPq, and BRAIN Program from Biomin company. We thank Mrs Catherine Anne Moll for her help with the English text. The authors' contributions were as follows: I. P. O., A.-P. F. L. B., B. G., W.- D. M. and G. S. conceived and designed the experiments; A.-P. F. L. B., J. L., B. G. and G. D. P. performed the experiments; A.-P. F. L. B., B. G. and I. P. O. analysed the data; I. P. O. and A.-P. F. L. B. wrote the manuscript. The authors have no conflict of interest. 


\section{References}

1. Shephard GS (2008) Determination of mycotoxins in human foods. Chem Soc Reviews 37, 2468-2477.

2. Oswald IP \& Comera C (1998) Immunotoxicity of mycotoxins. Rev Med Vet 149, 585-590.

3. Binder EM, Tan LM, Chin LJ, et al. (2007) Worldwide occurrence of mycotoxins in commodities, feeds and feed ingredients. Anim Feed Sci Technol 137, 265-282.

4. Schothorst RC \& van Egmond HP (2004) Report from SCOOP task 3.2.10 'collection of occurrence data of Fusarium toxins in food and assessment of dietary intake by the population of EU member states' - Subtask: trichothecenes. Toxicol Lett 153, 133-143.

5. Smith TK, McMillan EG \& Castillo JB (1997) Effect of feeding blends of Fusarium mycotoxin-contaminated grains containing deoxynivalenol and fusaric acid on growth and feed consumption of immature swine. J Anim Sci 75, 2184-2191.

6. Grenier B \& Oswald IP (2011) Mycotoxin co-contamination of foods and feeds: meta-analysis of publications describing toxicological interactions. World Mycotoxin J 4, 285-313.

7. Bouhet S \& Oswald IP (2005) The effects of mycotoxins, fungal food contaminants, on the intestinal epithelial cell-derived innate immune response. Vet Immunol Immunopathol $\mathbf{1 0 8}$, 199-209.

8. Maresca M \& Fantini J (2010) Some food-associated mycotoxins as potential risk factors in humans predisposed to chronic intestinal inflammatory diseases. Toxicon $\mathbf{5 6}$, 282-294.

9. Voss KA, Smith GW \& Haschek WM (2007) Fumonisins: toxicokinetics, mechanism of action and toxicity. Anim Feed Sci Technol 137, 299-325.

10. Halloy DJ, Gustin PG, Bouhet S, et al. (2005) Oral exposure to culture material extract containing fumonisins predisposes swine to the development of pneumonitis caused by Pasteurella multocida. Toxicology 213, 34-44.

11. Wang H, Wei H, Ma J, et al. (2000) The fumonisin B1 content in corn from North China, a high-risk area of esophageal cancer. J Environ Pathol Toxicol Oncol 19, 139-141.

12. Goope NV, He Q \& Sharma RP (2003) Fumonisin B1-induced apoptosis is associated with delayed inhibition of protein kinase $\mathrm{C}$, nuclear factor-kappaB and tumor necrosis factor alpha in LLC-PK1 cells. Chem-Biol Interact 146, 131-145.

13. Schmelz EM, Dombrink-Kurtzman MA, Roberts PC, et al. (1998) Induction of apoptosis by fumonisin B1 in HT29 cells is mediated by the accumulation of endogenous free sphingoid bases. Toxicol Appl Pharmacol 148, 252-260.

14. Bouhet S, Le Dorze E, Pérès SY, et al. (2006) Mycotoxin fumonisin $B_{1}$ selectively down-regulates the basal IL-8 expression in pig intestine: in vivo and in vitro studies. Food Chem Toxicol 44, 1768-1773.

15. Taranu I, Marin DE, Bouhet S, et al. (2005) Mycotoxin fumonisin B1 alters the cytokine profile and decreases the vaccinal antibody titer in pigs. Toxicol Sci 84, 301-307.

16. Marin DE, Taranu I, Pascale F, et al. (2006) Sex-related differences in the immune response of weanling piglets exposed to low doses of fumonisin extract. Br J Nut 95, 1185-1192.

17. Pestka JJ \& Smolinski AT (2005) Deoxynivalenol: toxicology and potential effects on humans. J Toxicol Environ Health B Crit Rev 8, 39-69.

18. Pinton P, Accensi F, Beauchamp E, et al. (2008) Ingestion of deoxynivalenol (DON) contaminated feed alters the pig vaccinal immune responses. Toxicol Lett 177, 215-222.

19. Accensi F, Pinton P, Callu P, et al. (2006) Ingestion of low doses of deoxynivalenol does not affect hematological, biochemical, or immune responses of piglets. J Anim Sci 84, 1935-1942.

20. Pestka JJ, Zhou HR, Moon Y, et al. (2004) Cellular and molecular mechanisms for immune modulation by deoxynivalenol and other trichothecenes: unraveling a paradox. Toxicol Lett 53, 61-73.

21. Maresca M, Yahi N, Younès-Sakr L, et al. (2008) Both direct and indirect effects account for the proinflammatory activity of enteropathogenic mycotoxins on the human intestinal epithelium:stimulation of interleukin- 8 secretion, potentiation of interleukin-1beta effect and increase in the transepithelial passage of commensal bacteria. Toxicol Appl Pharmacol 228, 84-92.

22. Pinton P, Nougayrede JP, Del Rio JC, et al. (2009) The food contaminant deoxynivalenol, decreases intestinal barrier permeability and reduces claudin expression. Toxicol Appl Pharmacol 237, 41-48.

23. Van De Walle J, Sergent T, Piront N, et al. (2010) Deoxynivalenol affects in vitro intestinal epithelial cell barrier integrity through inhibition of protein synthesis. Toxicol Appl Pharmacol 245, 291-298.

24. Grenier B, Loureiro-Bracarense AP, Lucioli J, et al. (2011) Individual and combined effects of subclinical doses of deoxynivalenol and fumonisins in piglets. Mol Nutr Food Res 55, 761-771.

25. Kolf-Clauw M, Castellote J, Joly B, et al. (2009) Development of a pig jejunal explant culture for studying the gastrointestinal toxicity of the mycotoxin deoxynivalenol: Histopathological analysis. Toxicol in vitro 23, 1580-1584.

26. Pinton P, Braicu C, Nougayrede JP, et al. (2010) Deoxynivalenol impairs porcine intestinal barrier function and decreases the protein expression of claudin- 4 through a mitogen activated protein kinase dependent mechanism. J Nut 140, 1956-1962.

27. Oswald IP, Dozois CM, Barlagne R, et al. (2001) Cytokine mRNA expression in pigs infected with Schistosoma japonicum. Parasitology 122, 299-307.

28. Devriendt B, Gallois M, Verdonck F, et al. (2009) The food contaminant fumonisin B-1 reduces the maturation of porcine CD11R1(+) intestinal antigen presenting cells and antigen-specific immune responses, leading to a prolonged intestinal ETEC infection. Vet Res 40, 40.

29. Kubena LF, Edrington TS, Harvey RB, et al. (1997) Individual and combined effects of fumonisin B1 present in Fusarium moniliforme culture material and T-2 toxin or deoxynivalenol in broiler chicks. Poultry Sci 76, 1239-1247.

30. Bouhet S \& Oswald IP (2007) The intestine as a possible target for fumonisin toxicity. Mol Nutr Food Res 51, 925-931.

31. Wang E, Norred WP, Bacon CW, et al. (1991) Inhibition of shingolipid biosynthesis by fumonisins. Implications for diseases associated with Fusarium moniliforme. I Biol Chem 266, 14486-14490.

32. Awad WA, Böhm J, Razzazi-Fazeli E, et al. (2006) Effects of feeding deoxynivalenol contaminated wheat on growth performance, organ weights and histological parameters of the intestine of broiler chickens. J Anim Physiol Animal Nutr 90, 32-37.

33. McGuckin MA, Linden SK, Sutton P, et al. (2011) Mucin dynamics and enteric pathogens. Nat Rev/Microbiol 9, 265-278.

34. Piva A, Casadei G, Pagliuca G, et al. (2005) Activated carbon does not prevent the toxicity of culture material containing fumonisin B 1 when fed to weanling piglets. J Anim Sci 83, 1939-1947. 
35. Brown $T$, Rottinghaus $G$ \& Williams M (1992) Fumonisin mycotoxicosis in broilers: performances and pathology. Avian Dis 36, 450-454.

36. Theumer MG, Lopez AG, Masih DT, et al. (2002) Immunobiological effects of fumonisin B1 in experimental subchronic mycotoxicoses in rats. Clin Diagn Lab Immunol 9, 149-155.

37. Bouhet S, Hourcade E, Loiseau N, et al. (2004) The mycotoxin fumonisin B1 alters the proliferation and the barrier function of porcine intestinal epithelial cells. Toxicol Sci 77, 165-171.

38. Chen F, Ma Y, Xue C, et al. (2008) The combination of deoxynivalenol and zearalenone at permitted feed concentrations causes serious physiological effects in young pigs. $J$ Vet Sci 9, 39-44.

39. Shifrin VI \& Anderson P (1999) Trichothecene mycotoxins trigger a ribotoxic stress response that activates c-Jun $\mathrm{N}$-terminal kinase and p38 mitogen-activated protein kinase and induces apoptosis. J Biol Chem 274, 13985-13992.

40. Stadnyk AW (2002) Intestinal epithelial cells as a source of inflammatory cytokines and chemokines. Can J Gastroenterol 16, 241-246.

41. Azcona-Olivera JI, Ouyang Y, Murtha J, et al. (1995) Induction of cytokine mRNAs in mice after oral exposure to the trichothecene vomitoxin (deoxynivalenol): relationship to toxin distribution and protein synthesis inhibition. Toxicol Appl Pharmacol 133, 109-120.

42. Dugyala RR, Sharma RP, Tsunoda M, et al. (1998) Tumor necrosis factor- $\alpha$ as a contributor in fumonisin B1. J Pharmacol Experim Therap 285, 317-324.

43. Bhandari N, Brown CC \& Sharma RP (2002) Fumonisin $\mathrm{B}_{1}$-induced localized activation of cytokine network in mouse liver. Food Chem Toxicol 40, 1483-1491.

44. Van Cruchten S \& Van den Broeck W (2002) Morphological and biochemical aspects of apoptosis, oncosis and necrosis. Anat Histol Embryol 31, 214-223.

45. Ye D, Ma I \& Ma TY (2006) Molecular mechanism of tumor necrosis factor- $\alpha$ modulation of intestinal epithelial tight junction barrier. Am J Physiol Gastrointest Liver Physiol 290, 496-504.
46. Al-Sadi R, Ye D, Dokladny K, et al. (2008) Mechanism of IL-1beta induced increase in intestinal epithelial tight junction permeability. J Immunol 180, 5653-5661.

47. Hershberg RM \& Mayer LF (2000) Antigen processing and presentation by intestinal epithelial cell-polarity and complexity. Immunol Today 21, 123-128.

48. Soderholm JD, Olaison G, Peterson KH, et al. (2002) Augmented increase in tight junction permeability by luminal stimuli in the non-inflamed ileum of Crohn's disease. Gut $\mathbf{5 0}$, 307-313.

49. Luongo D, De Luna R, Russo R, et al. (2008) Effects of four Fusarium toxins (fumonisin B(1), alpha-zearalenol, nivalenol and deoxynivalenol) on porcine whole-blood cellular proliferation. Toxicon 52, 156-162.

50. Speijers GJ \& Speijers MH (2004) Combined toxic effects of mycotoxins. Toxicol Lett 153, 91-98.

51. Pinelli E, Poux N, Garren L, et al. (1999) Activation of mitogen-activated protein kinase by fumonisin $\mathrm{B}(1)$ stimulates CPLA(2) phosphorylation, the arachidonic acid cascade and cAMP production. Carcinogenesis 20, 1683-1688.

52. Dong C, Davis RJ \& Flavell RA (2002) MAP kinases in the immune response. Annu Rev Immunol 20, 55-72.

53. Pestka JJ \& Zhou HR (2000) Interleukin-6-deficient mice refractory to IgA dysregulation but not anorexia induction by vomitoxin (deoxynivalenol) ingestion. Food Chem Toxicol 38, 565-575.

54. Royaee AR, Husmann RJ, Dawson HD, et al. (2004) Deciphering the involvement of innate immune factors in the development of the host response to PRRSV vaccination. Vet Immunol Immunopathol 102, 199-216.

55. Meissonnier GM, Pinton P, Laffitte J, et al. (2008) Immunotoxicity of aflatoxin B1: Impairment of the cell-mediated response to vaccine antigen and modulation of cytokine expression. Toxicol Appl Pharmacol 231, 142-149.

56. Meurens F, Berri M, Auray G, et al. (2009) Early immune response following Salmonella enterica subspecies enterica serovar Typhimurium infection in porcine jejunal gut loops. Vet Res $\mathbf{4 0}, 5$. 